associations within the SRA and continues co-operation in seminars, conferences and medical projects.

Conclusions At the moment the only possible conclusions to be drawn are about the preparation process and we can identify a great interest from our members and Apoteket $\mathrm{AB}$ to carry out a successful thematic year together.

\section{Arthritis/rheumatism as a public health issue}

\section{SP0152 WHY CAMPAIGNING IS GOOD FOR ARTHRITIS!}

N Betteridge. Head of Public Policy and Campaigning Arthritis Care, UK

10.1136/annrheumdis-2001.1281

The paper will explain why people with arthritis are beginning to campaign in new ways and how this can benefit themselves as individuals, the community of people with arthritis and society as a whole.

It will explore the sometimes fractious, and still evolving, history of how people with arthritis have gradually moved away from seeing themselves in an entirely medical context; but also how the social model of disability has been both a liberation and a limitation. The energies of people with arthritis have been released by developing a vision where we are more than just patients or passive recipients of care. We now know that we can be actively involved in managing our condition and have a right to be actively involved in society. But where is that release of energy taking us?

Citing anti-discrimination legislation in both the UK and the USA, the paper will seek to summarise the public policy position for people with arthritis in 2001 but will also be forward looking. Does the advent of new technologies mean that science once more becomes the focus for people with arthritis? Or will the links with the civil rights movement of disabled people strengthen and grow so that medicine will be overshadowed by a political drive based entirely on social issues?

The speaker, Neil Betteridge, has personal experience of arthritis and is Head of Public Policy and Campaigning at Arthritis Care in the UK. Whilst working for the Royal Association for Disability and Rehabilitation (RADAR) he was involved in campaigning for, and helping to influence, the Disability Discrimination Act 1995. He is currently actively involved in the European Manifesto for People with Arthritis and Rheumatism in Europe.

\section{SP0161 WHY RHEUMATIC DISEASES ARE UNDERESTIMATED IN POLAND?}

B Moskalewicz. Institute of Rheumatology, Warsaw, Poland

10.1136/annrheumdis-2001.1282

Poland has a population of 38 millions people, what means an eighth rank among 43 European countries. When 5 million (13\% of total population) suffer from chronic rheumatic problems and rheumatic diseases constitute the first cause of disability, arthritis should be defined as public health problem at the national and prehaps European level too. Unfortunately, public opinion is under the pressure of clinical, individual approach to health care.
Individualisation of health issues produces invisible social dramas, id est: social isolation of disabled, enormous bureaucratic disfunctions of care system and also shifting out cost of treatment to patients' family. Rheumatic patients have serious troubles to maintain satisfying personal relations and to participate in religious or social/political life. Those results of chronic rheumatic diseases are usually neglected in public dispute on health priorities.

Three "curtains" exist in public health theatre making difficult to perceive rheumatic problems:

- social attitudes towards disability

- self marginalisation of arthritis patients

- family support instead of systemic resolutions.

Governmental agencies, using a traditional model of public activity are highly bureaucratic: centralised, impersonal, hierarchical and specialised. Self-help groups are quite opposite: locally centred, personal, non-hierarchical and non-specialised. The two actors of public health performance act in different ways and their political influence changes. As governmental agencies failed so far to remove all three courtains, it is time for NGOs to play a crucial role.

\section{Other inflammatory arthritides}

\section{HP0009 AUDIT OF A RHEUMATOLOGY NURSE SPECIALIST (RNS) SHOULDER INJECTION CLINIC}

WD Pointer, PL Williams. Rheumatology, Medway Maritime Hospital, Kent, UK

10.1136/annrheumdis-2001.1283

In order to shorten waiting times for referrals for shoulder pain, we have set up a dedicated clinic, run by a RNS trained in assessment and management of shoulder problems, including injection of corticosteroid, to which all consecutive new patients, who were thought likely from the letter of referral to benefit from an injection were allocated. Diagnosis was discussed and confirmed with the Rheumatologist.

The results of the first 56 patients $(23$ male) to attend have been audited.

Diagnosis was as follows:

Adhesive Capsulitis 21, Supraspinatus Tendonitis 11, Rotator Cuff Lesion 7, Non-specific shoulder pain 5, Occupation related shoulder pain 3, Bicipital Tendonitis 3, Thoracic outlet compression 1, Acromioclavicular joint pain 1, Posture related shoulder pain 1, Fibromyalgia 1, Referred pain from hepatic secondaries 1 , Secondary deposit 1.

In 18 patients (32\%) the clinic and GP diagnoses were the same. In $16(28.6 \%)$ they differed and in $22(37.5 \%)$ the GP letter indicated painful shoulder but no specific diagnosis.

Of these patients $36(64 \%)$ were treated with injection. The remaining $20(36 \%)$ were not injected for the following reasons: Symptoms resolved 12, Patient declined 3, Inappropriate 4, Reason not recorded 1.

Of the 56 patients audited, 49 were available for review by telephone at a minimum of 3 months after initial visit. The results of this interview showed that 17 had complete resolution of symptoms, 21 had more than 50\% improvement, 1 less than $50 \%$ improvement, 5 said their symptoms were unchanged and 5 stated their symptoms were worse. 